\title{
The Expansion of Social Security in Italy
}

\author{
by Lucia Vitali *
}

The role of social security in the Italian economy is constantly increasing in importance : from the financial point of view, because it is financed to a large extent by the State and by the wealthiest components of the industrial world; from the social point of view, because it has by now expanded so as to cover the whole population, including the non-employed, and from the economic point of view, because the effects of social security provisions, through income transfers operated by public finance, help to maintain domestic demand at a high level.

In order to understand better some of the many aspects of the Italian system of social security, and its complex influence on the national community, this paper indicates some of the reasons for the present development of compulsory social services provided by the State, beginning with an analysis of the two main components of social expenditure, i.e. pensions and health care.

\section{Pension schemes}

The Italian pension system has developed rather slowly. It began during the early twenties in the form of group social insurance, and continued to progress in the thirties, when it underwent more consistent expansion through funds which were based mostly on the accumulation of contributions.

By 1952 the Italian pension system was extended to all dependent workers of both the public and private sectors. Essentially, it covered those employees with greater job security and higher, or more stable, earnings.

The system was formed by a variety of bodies governed by the social insurance principle. Funds were administered in accordance with actuarial equity, even though the rules were different from those in force before the war because of the high inflation which had meanwhile developed 1 .

The years that followed were essentially marked by rapid growth, and the economic context of the fifties shows a favourable picture of industrial development and price stability. In that situation, two different kinds of development took place in social insurance.

* Assistant Professor, University of Rome.

1 Pensions had been funded during the period before the Second World War. Mainly because of inflation, they have been subsequently administered according to the pay-as-you-go principle. 
On the one hand, according to the insurance system rules which require benefits to correspond to the sum-total of contributions, some new pension funds were set up in addition to, and sometimes in substitution of, the State scheme. They were based mainly on funding; the categories concerned are to be found chiefly in the major banking institutions and industrial enterprises. These development took place in a comparatively limited area, although it proved capable of significant capital formation in the funds concerned. It soon slowed down, mainly due to an expansion of the State scheme.

The other kind of development concerned the expansion of the compulsory pension scheme, which had been relatively limited up to that time.

The progress of economic growth, leading to the boom of the early sixties, favoured an extension of social security benefits to a larger number of workers. It was time for the self-employed to come into the system, i.e. agricultural workers, craftsmen and - a few years later - shopkeepers. The result was a broadening of the solidarity effect of social security from the wide group of private dependant workers to the three groups of self-employed just mentioned.

The rapid growth in the industrial sector was determining a shift towards dependant work conditions within the active population. Therefore, forecasts indicated an increase in the number of people insured in the State scheme while the opposite trend was expected among the self-employed, especially in agriculture, where a marked reduction in the number of insured workers took place.

In this perspective, the contribution of dependant workers to the cost of the pension scheme for the self-employed seems perfectly acceptable and appropriate. Moreover, the pay-as-you-go method used for the private sector workers proved particularly suited to a wider solidarity.

In the case of the liberal professions (doctors, lawyers, etc.), each profession has a specific pension fund.

It follows that, since 1966 (the year self-employed shopkeepers were included), the whole of the active population, in all sectors of activity, was covered by social insurance with respect to pensions for old age, invalidity and survivors.

In the second half of the sixties, social security further enlarged its area of application.

The "minimum pension" was introduced. This is a flat-rate pension which applies to dependant and self-employed workers whose contributions would have entitled them to a smaller sum. This fixed amount is adjusted every year to the index of the contractual wage of industrial workers 2 .

A second flat-rate benefit was introduced in 1969 for indigent persons who have never made any payment to social insurance. Of the beneficiaries of this "social pension ", $90 \%$ are women.

2 The minimum pension can be paid either as a retirement or as an invalidity benefit. Entitlement to the former is acquired after 15 years of paid contributions, to the latter after 5 years only. 
Pensions paid by the Italian system can be classified as follows :

- earnings-related pensions, which can be considered as a deferred salary;

- flat-rate pensions, which have a strong social assistance connotation.

The various bodies which administer pensions and contributions for the different groups derive their funds from employers, workers and the State. The contributions paid by the employer and the employee vary from one fund to another, and sometimes even within a particular fund. The table in the appendix summarizes the main features of the chief components of the Italian pension system.

As a whole, in 1976, pension funds were financed $49 \%$ by the employers, $24 \%$ by the State and $37 \%$ by workers 3 .

The State contributes to the financing of the general scheme through a "social fund ". State money covers the total payment of the cost of social pensions for indigent aged persons. It also covers part of the cost of all other pensions for the self-employed and the private sector employees. This partial payment is equal to 12000 lire for each recipient of a pension.

The number of pensions, the total amount of the expenditure and its incidence on gross domestic product have continuously increased since 1960:

$\begin{array}{ccccc}\text { No. of pensions } & \text { Total expenditure } \\ \text { (thousands) } a & \begin{array}{c}\text { G.N.P. } \\ \text { (billion lire) }\end{array} & \begin{array}{c}\text { \% incidence of } \\ \text { (billion lire) }\end{array} & \begin{array}{c}\text { expenditure on GNP } \\ 1960\end{array} \\ 5700 & 1050 & 21632 & 4.85 \\ 1965 & 7420 & 2500 & 36530 & 6.84 \\ 1970 & 10390 & 4550 & 57937 & 7.85 \\ 1975 & 13000 & 12370 & 114215 & 10.83 \\ 1976 & 13280 & 15630 & 142128 & 11.00 \\ 1977 & 13550 & 18800 & 172000 & 10.93\end{array}$

a Exluding war pensions.

The increase in expenditure may also be deducted from the increase in the average amount of the retirement pension in the general scheme, where the lowest percentage $(54 \%)$ of "minimum pensions" is to be found 4 .

3 The 1977 average contribution of a dependant worker was estimated at 800000 lire (about 1000 US \$); the flat-rate contribution for the pensions of a self-employed person was 95000 (110 US \$); the yearly rate for farmers was 60000 (75 US \$) only. For the majority of dependant workers and for $98 \%$ of the self-employed, pensions are granted at the minimum level, i.e. at a flat rate, the same for all beneficiaries. It must be noted that more than $40 \%$ of all pension benefits are invalidity pensions. The flat rate for dependant workers, however, is slightly higher $(10 \%$ more) than that of self-employed pensioners. For a detailed analysis see [1] and [2].

4 A much higher percentage of flat-rate benefits $(84 \%)$ is to be found among invalidity benefits granted under the general scheme. Flat-rate disablement benefits have a stronger "assistential" connotation than the flat-rate retirement benefits. 
As compared with per capita income, retirement pensions under the State scheme show an increasing importance :

\begin{tabular}{|c|c|c|c|}
\hline $\begin{array}{l}\text { Average yearly amount } \\
\text { of retirement pensions }\end{array}$ & $\begin{array}{l}\text { Per capita } \\
\text { income }\end{array}$ & $\begin{array}{c}\text { Ratio } \\
(1):(2)\end{array}$ & $\begin{array}{l}\text { Index No. of retirement } \\
\text { pensions at } 1976 \text { prices }\end{array}$ \\
\hline
\end{tabular}

(1)

1960

1965

1970

1975

1976
158.1

322.8

471.1

1047.1

1275.9
(2)

395.1

644.9

991.0

1828.2

2266.3
40.0

50.1

47.5

57.3

56.3
100.0

159.0

203.0

264.0

276.5

Source : Istituto Nazionale della Previdenza Sociale, Allegati Statistici ai rendiconti dell'anno 1976, Roma, 1977, pp. 39 e 40.

Almost all pension benefits for self-employed persons, i.e. $98 \%$ of them, and $63 \%$ of all types of pensions (old age, invalidity and survivors') granted under the general scheme are flat-rate. The great majority of minimum pensions for the selfemployed are in the form of invalidity benefits. These amounts have also increased at a significant pace :

Minimum monthly benefits (current values) *

\begin{tabular}{|c|c|c|c|c|c|}
\hline & \multicolumn{2}{|c|}{$\begin{array}{lc}\text { Dependant } & \text { worker } \\
\text { current } & \text { index } \\
\text { values } & \text { number }\end{array}$} & $\begin{array}{l}\text { Self-er } \\
\text { current } \\
\text { values }\end{array}$ & $\begin{array}{l}\text { yed } \\
\text { index } \\
\text { number }\end{array}$ & $\begin{array}{l}\text { Contractual wage } \\
\text { industrial worker } \\
\text { index number }\end{array}$ \\
\hline 1966 & 19500 & 100 & 12000 & 100 & 100.0 \\
\hline 1970 & 25000 & 128 & 18000 & 150 & 142.5 \\
\hline 1975 & 55950 & 287 & 47800 & 398 & 344.3 \\
\hline 1976 & 66950 & 343 & 66950 & 558 & 416.3 \\
\hline 1977 & 79650 & 408 & 76950 & 641 & $555.7^{a}$ \\
\hline 1978 & 102500 & 526 & 91100 & 759 & - \\
\hline
\end{tabular}

Sources : I.N.P.S. Statistics, and Ministero del Lavoro for data on wages.

* It must be noted that 13 payments are made in a year.

a Estimated value.

This expanding trend of the pension system has resulted in a deterioration of the ratio of pensions to active population. The number of active persons has remained practically constant since 1960 , i.e. nearly 21 million persons. On the other hand, the number of pensions has more than doubled, since it was nearly 6 millions in 1960 and it is now about 14 millions. Actually, the total number of pensions, including all kinds of war and work disability pensions, is over 16 millions. In particular, the estimate for the self-employed in agriculture (as predicted in the fifties) proved quite correct, since the ratio of pensioners to active workers, for that particular scheme, is higher than 1.

It must be stressed that, for pensions as for other State social security schemes, the extension of the population coverage took place in the total absence of a prior reorganization and rationalization. Funds administering pensions receive contributions 
which are related to earnings in different percentages, but mostly concentrated around $22-24 \%$ of earnings. Lower percentages are to be found in minor funds where the ratio of pensioners to insured persons is more favourable.

The spreading of benefits has brought about a situation that, among Western European countries, is to be found only in Italy: that is the fact that contributions are based on the entire gross earnings, without any maximum ceiling (flat-rate contributions are obviously excluded).

In other words, the social security contributions for any scheme and any type of benefit are paid on the whole salary received by the dependant worker, however high its amount. On the contrary, a ceiling exists for the payment of pensions in the general scheme. Its amount was fixed a few years ago and its value today is about double the average salary for an industrial worker. The higher income white collar workers can sometimes contribute more than they receive; this ceiling will most likely be raised by the probable enactment of a recent government bill 5 .

\section{Health care}

Health care is also provided by one large body, the "Istituto Nazionale per l'Assicurazione contro le Malattie" and a number of smaller ones, which cover small groups of workers not covered by the general scheme. Minor health assistance bodies cover the liberal professions and the self-employed.

The most recent phase of expansion in health insurance coverage concerns selfemployed farmers (since 1955), craftsmen (1957) and shopkeepers (1961).

Civil service pensioners have been entitled to free health care since 1953, and pensioners of the private sector and of local authorities since 1954. A few years later this care was extended also to pensioners of the self-employed groups.

Lately, health insurance has been extended also to those who do not have, and to those who never had, an employment, e.g. social pensioners and civilian disabled persons, who have been entitled from 1972 and 1974 respectively to free health assistance.

Social security contributions for health insurance are paid by employers and employees in different proportions. The employer pays $12.85 \%$ of the salary for blue collar workers and $10.85 \%$ for white collar workers.

5 An interesting peculiarity of the Italian system is its provision for a severance payment called "indennità di anzianità ". It entitles a dependant worker, at the end of his working life, to receive a lump sum equal to the last monthly salary, multiplied by the number of his years of service. It is a special form of deferred earnings created when social security coverage was limited. The social and economic aims of this practice are outdated in a context aiming at a constantly improved protection of the employee. The accumulation of the relative amounts is done by the employer; when inflation had not yet reached the present level, it was considered an easy source of self-financing. Today it constitutes a heavy burden for the employer, as its special adjustment mechanism, based on the most recent salary rates, obliges the employer to make yearly revaluations of all amounts accumulated for each employee. 
On the employee side, the contribution is nearly $1 \%$ of earnings. The State bears the major part of the burden, since hospital costs are entirely borne by public expenditure, and so is the difference between total health expenses and social security contributions.

As a whole, the public health programme covers about 54 million inhabitants, i.e. over $95 \%$ of the total population.

The health insurance scheme has been expanded without any selectivity measures, and has resulted in a costly item in the public expenditure budget.

Practically no control or restraint is placed on these services, and suspicions have been voiced of harmful waste of public money. The highest increases have been registered in the use of hospital beds : the duration of hospitalization is among the longest in Western Europe. Overconsumption of medicines is also a problem.

The increasing burden of health expenses, at current values, is shown by the following table :

Public health expenditure Gross national product Expenditure/GNP

1962 (billion lire) (billion lire)

1968 629

27303

Source : Eurastat, Conti sociali, Bruxelles 1977 and 5th appendix to the Relazione generale ed economica, Roma 1977.

The growth of public health expenditure is also indicated by the elasticity of this expense as compared to national product. On average, in the last ten years, it has been higher than 1.5 .

Apart from the growing frequency in the use of the various services, other reasons account for the increased expenditure on health. Higher costs for new technologies and more sophisticated health appliances, especially in the hospital sector, are a worrying component of the health item. Hospitals, in fact, account for over $50 \%$ of the total health expenditure.

The cost of labour is another major component. The health sector is obviously labour intensive, since nearly all services rendered need the attention of at least one person. 
Above all, however, the extension of coverage to new groups of the population, especially the old, creates a high demand for this kind of benefit. Old people show in fact the highest frequency in both medical and hospital care ${ }^{6}$.

It has been argued that the excessive extension of the concept of social security can have a growing impact on expenditure in sickness cash benefits. Such a situation has, in fact, occurred in Italy, where a considerable increase has been registered in this kind of benefit. In the seven years from 1970 to 1976 benefits have quadrupled, growing from 294 to 1133 billion lire.

\section{The process of expansion}

The two major expenses in Italian social security just described have increased in importance since the mid-sixties. Since then, the difficult economic situation has created a favourable situation for an increase in expenditure on social benefits aimed at offsetting social tensions caused by the slowing down of the previously rapid economic growth.

In pensions, in particular, attention has been devoted to increasing their number and amount. At the same time, contributions have been raised substantially. The relation between benefits and contributions has become less binding. The computation of the pension is now related to the length of service and to the level of the last salary (or, more precisely, the highest average earnings of the last period of employment). The pension scheme has therefore nearly lost, for certain benefits, its character of a social insurance institution; assistance criteria now prevail.

"Two different streams became identifiable inside the Italian social security system. The first originates from an insurance matrix, where benefits are paid against contributions which cover definite risks: the second has a more precise connotation of assistance, where social security has a role of public service, and inside which the benefits received are paid by the national community" [3]. This statement gives an appropriate picture of the present developments. Additions have in fact been made to the social insurance system covering the vast majority of employed persons, so that no separate body has been created for assistance benefits. Recipients who have never contributed, either through the pay-as-you-earn system or through direct taxes, are in the same scheme as the tax-paying working population. Their benefits are paid by the central body, where traces can be found of the "insurance matrix", a criterion still followed to a large extent with regard to earnings-related benefits. The obvious advantage of a mixed administration lies in a notable saving in administrative expenses.

6 The importance of demographic aspects in social security is well known. An OECD study (Old age pensions, Paris 1977) has recently confirmed that in the next few years the percentage of the Italian population above 65 will remain around the present $12 \%$ of total population. This study has also made an evaluation of the ratio between non-active aged persons and the active population. This ratio will be as high as $33.2 \%$ in 1980 and $31.5 \%$ in 1985 (higher than in the other OECD countries examined). Obviously, the activity rate of the aged will tend to decrease constantly and will be as low as $5 \%$ in the eighties (lower than the average rate for the other OECD countries). 
With this development of social policy, economic security has practically been guaranteed to the whole population, although at different levels. This result has been achieved, however, with little constraint as to the entitlement of "assistance" benefits, and clearly disregarding the traditional rule: "to each according to his needs, from each according to his means".

The extention of social security coverage has brought together non-working and working persons, in a system which, based as it is on the social insurance principle, refers in its provisions to the individual recipient and not to his family circumstances. With reference to the economic situation of the family in which the beneficiary lives, such a principle can produce serious distortions when the benefits received is a flat-rate one. Whether the household lives in poverty or not, the benefit received does not change in amount. No supplementary State assistance is permanently granted to the poor (although a number of temporary aids from charitable institutions are available), nor does the State require a rigid test of financial means to determine eligibility for payments totally or partially coming from the social fund, that is out of public monies.

It must be stressed that the rapid increase in the amount of pensions is due partly to increases decided by the government but mostly to a method of automatic adjustment for changes in earnings (in contractual pay for the minimum benefit). The adequacy of the benefits for pensions above the minimum is maintained by adjusting their level to the increase both in earnings and in prices.

This is a complex method of adjustment, particularly favourable to the recipient. It has allowed the purchasing power of pensions in recent years not only to maintain its position in real terms, but also to increase. The elasticity of pensions to national product is, in fact, higher than unity.

A peculiarity of the Italian system, deriving from its extension, is the liberalization of the eligibility conditions for disability benefits. This involves a more favourable definition of disability (related to health status and to the capacity of finding a job in the area of residence), a shortening of the length of the contributory period and the permanency of the concept of disability in all accepted cases.

This generous attitude has, in practice, turned most disability benefits into income maintenance provisions, especially in underdeveloped areas. In agriculture, slightly more than two million flat-rate pensions are paid to farmers, more than $72 \%$ of which are permanent disability benefits. The reasons for this diffusion of rural invalidity can be found in the desire to assist agricultural family income in the poorest regions and, generally, in the higher pensionable age in the self-employed schemes.

The extension of social security has also brought with it the generalized expansion of free health care. Only a few months ago this was attenuated by the introduction of a prescription charge on drugs, with the dual aim of restraining the overconsumption of drugs and of reducing the deficit in the public health budget.

In spite of the comprehensive system of health care, private medicine has a remarkable importance in the whole country, especially with reference to specialist and hospital treatment. The forthcoming approval of the law for the creation of a national health service is expected to standardize more evenly, at the national level, the present forms of public health care, thus allowing the private sector to gain new ground for a diversified care in health services. 


\section{Economic and financial consequences of social security expansion}

It has already been stressed that higher costs deriving from the expansion of the system were covered since the post war period by the elimination of the earnings ceiling for the purpose of calculating contributions. The employers' quota is also higher (at least double) than that of the employees. The distinction between the two sources in the payment of contributions has a limited significance, however, since both elements enter into the cost of labour, which is borne in the end by the employer.

The State share has also reached a considerable percentage of the total contributions for social services. In 1976, the total amount of contributions reached 23000 billion lire and $16.8 \%$ of this was paid by the State. About $90 \%$ of this collective burden went to pension benefits.

The State share of the financing may sometimes be paid only in part, or be delayed for a certain period, because of budgetary or political reasons. If the required amount is paid with a certain delay, an advance payment is made by the pay-as-youearn pension funds. That is, the general scheme surplus is used to make up for the temporary absence of the State contribution.

On the other hand, the State contribution has become greater every year. Because of its increase, pressures for greater selectivity in the payment of benefits are gaining ground. Both experts and public opinion are demanding that those who have a sufficiently high income should not receive benefits (especially permanent ones) which are paid in ever increasing percentages by the national community.

As is well known, the tendency towards the extension of social security is based on the aim of achieving greater social justice. This target, however, can become more difficult to attain if the expansion makes no distinctions between the beneficiaries, allowing the largest possible number of them to get relatively small benefits.

The new enlarged system can easily create new inequalities, as long as it favours more those citizens who belong to the higher income brackets. In the present pension system, for instance, where the benefit is related to the most recent salary rate, some dependant workers with high final salaries can pay a lower amount of contributions and receive higher benefits than others. The minimum pension is, in most cases, almost entirely covered by the financial support of the whole community. In order to reach the fixed flat rate, an average financial integration of about $75 \%$ is needed. Beneficiaries of these pensions have paid very small contributions during their working lives, but this is not in itself evidence of financial need. They may well have other sources of income or even another pension granted by an institution outside the State scheme.

Therefore, as the social security expansion has taken place in a context of diversified pension regulations, there is the possibility that the public burden does not always work to the benefit of those in need.

The Italian system of social security has followed the main direction of extending coverage to the whole population, either through social insurance or public assistance, so as to allow minimum economic security to all. By this method, all groups of the population have been reached, including the poor. On the other hand, social benefits 
have been extended assistentially to citizens who already have, on their own, sufficient means.

It has been argued that this extension has taken place at the expense of voluntary insurance, which in Italy has always been of limited scope, even at a time when the benefits granted by social insurance covered only half the present social security beneficiaries.

The insurance market is bound by many controls on the part of the State, and by tight rules that do not favour its activity and dictate the type of investments made. The recent acceleration of inflationary pressures, moreover, has forced life insurance companies to stabilize their portfolios at a constant level, with a cautious attitude towards new acquisitions. At the same time, the economic system as a whole has reacted by favouring the expansion of social security, extending economic security to virtually the whole population.

The introduction of selectivity criteria in the payment of social benefits could, at the present time, contribute to a better distribution of the huge financial resources absorbed by the system. Higher benefits would be provided to those in need, verified by means tests. To the recipients with sufficient financial means payments would be in relation to contributions paid, adding a revaluation measure to allow for inflation. Mainly because of the costly adjustment system used for pension benefits, the present flat rates have reached a sufficiently high level to justify the cost of implementing selectivity measures. Such measures would certainly be of help in obtaining a better allocation of social expenditure.

The present inefficient mixture of social assistance and social insurance is one of the main reasons for the high cost of the Italian social services. A better distribution of income was the final aim, and the present system has actually brought about a higher degree of transfer payments from active and contributing population to the older generation.

This positive result has been achieved with no discrimination towards the higher income groups. Therefore, there is no equality between the marginal utility of beneficiaries and the loss of marginal utility of contributors. This positive result has brought with it two side effects which need urgent remedy: on the one hand, the frustration of private insurance, and on the other, a growing burden upon the active population.

Moreover, the effect of the acceleration of inflationary pressures due to the increase in social security contributions cannot be ignored. The imperfect working of the system of social benefits has therefore contributed to increase price instability, and the reaction to this effect is an increase in benefit levels and, therefore, in social security contributions. The vicious circle thus created is operating in the presence of a mechanism of automatic adjustments that can only accelerate its effects.

Apart from the project on a comprehensive health service, Parliament is at present discussing a draft law for the reorganization of pension benefits, aimed at reducing their share in the public expenditure. It involves the implementation of a less vigorous adjustment system ; it allows for the payment of a longer contribution period for those who choose to delay by five years their retirement age, and it provides for new restrictions, e.g. a number of penalties for wrongly directed payments of social pensions and a revision of the entitlement to disablement benefits. 
The future trend seems to be a move towards a two-tier system, similar to others in use in Western Europe. The public financing in these systems is usually limited to a minimum basic provision and higher benefits come from voluntary provisions, in the form of group insurance, i.e. based on the contributory principle.

The present experience proves that the State policy, by tending to guarantee an adequate level of income maintenance at public expense, has emphasized the redistributive function of the State budget. This positive effect involves the great disadvantage of a high degree of relative burden on the national budget. Greater efficiency can perhaps be achieved by giving absolute priority to the improvement of the conditions of persons actually in need and leaving to private group insurance improvements for those who already have a satisfactory standard of living.

\section{REFERENCES}

1. CASTELlino, O. Il Labirinto Delle Pensioni. Il Mulino, Bologna, 1976.

2. CASTEllinO, O. «La spesa per le pensioni », in Per Una Politica Della Spesa Pubblica In Italia, Franco Angeli, Milano, 1978.

3. PETRILLI, G. « Evoluzione del sistema previdenziale italiano verso la " sicurezza sociale "», Rivista degli Infortuni e delle Malattie Professionali, No 1, 1978. 


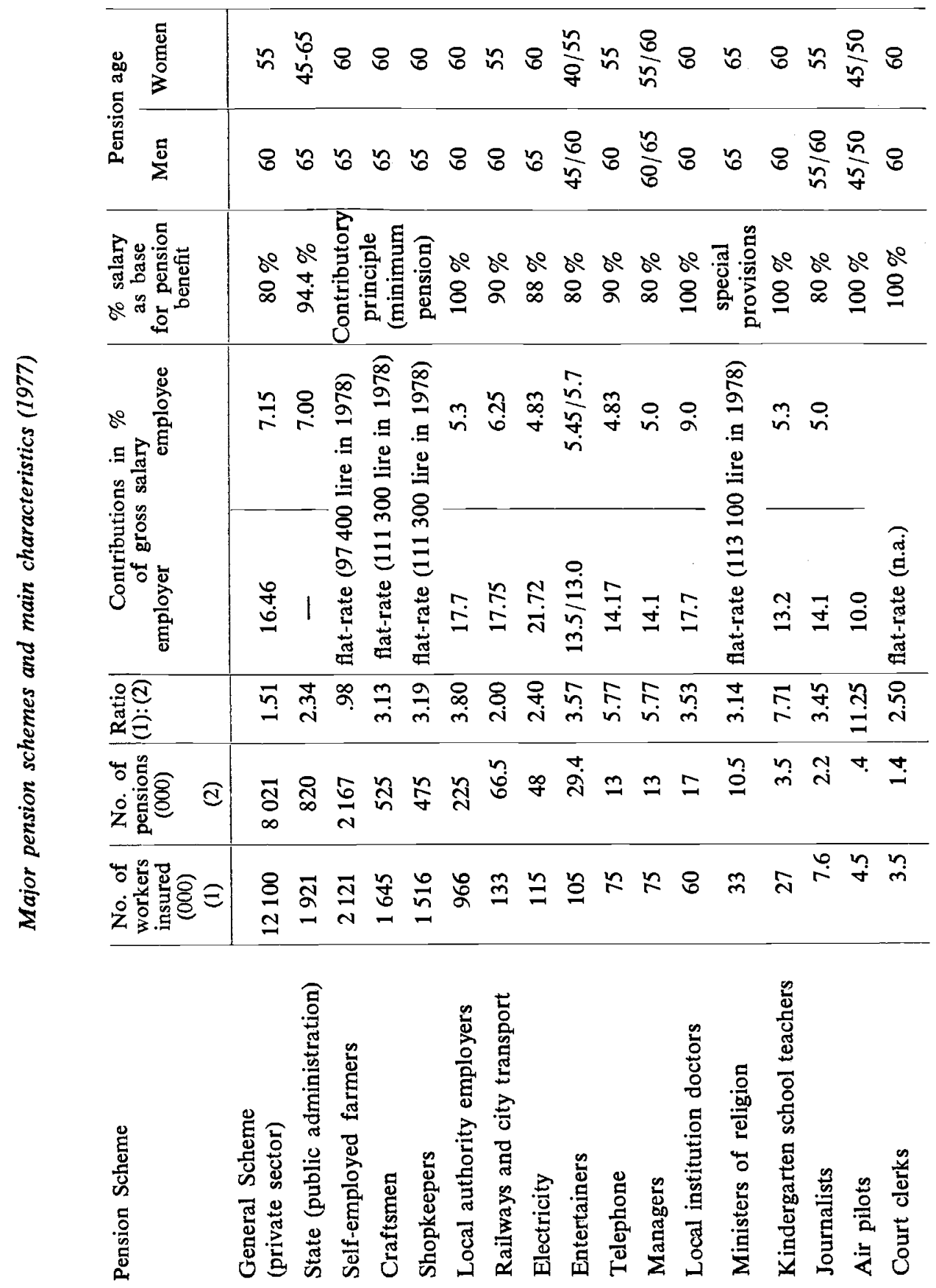

